MATEC Web of Conferences 47, 01006 (2016)

DOI: $10.1051 /$ matecconf/20164701006

(C) Owned by the authors, published by EDP Sciences, 2016

\title{
Rubberized Concrete Durability Against Abrasion
}

\author{
Nurazuwa Md Noor ${ }^{1, a}$, Daisuke Yamamoto ${ }^{2}$, Hidenori Hamada ${ }^{2}$ and Yasutaka Sagawa $^{2}$ \\ ${ }^{1}$ Jamilus Research Centre, Universiti Tun Hussein Onn Malaysia, 86400 Parit Raja, Johor, Malaysia \\ ${ }^{2}$ Department of Civil Engineering, Faculty of Engineering, Kyushu University, Nishi-Ku, Fukuoka 819-0395, Japan
}

\begin{abstract}
Durability performance of rubberized concrete against abrasion is presented in this paper. Surface depth loss was measured when abrasion load was constantly applied on concrete surface at each 500 interval rotation. Specimen with water-to cement ratio of 0.50 and 0.35 was prepared and tested at 28 days of curing age. In addition, $10 \%$ silica fume, SF was added to provide denser concrete and to understand its effectiveness against wear when added with crumb rubber. Results showed that crumb rubber shows good potential in providing abrasion resistance to concrete mix. However, in the case of rubberized concrete with silica fume, abrasion resistance was found to be slightly decreased with compressive strength more than $50 \mathrm{~N} / \mathrm{mm}^{2}$ due to the lack of low elastic modulus of CR particles to accommodate with denser cement matrix.
\end{abstract}

\section{Introduction}

Abrasion is described as the behavior of the construction element against destructive influences due to scraping, rubbing, skidding or sliding of the object on the surface which leads to surface erosion. Concrete durability is influenced by several factors such as concrete compressive strength, surfacing finishing, aggregate properties, types of hardeners and curing type [1]. The effectiveness of crumb rubber to improve wear resistance tested by using surface abrasion test is discussed in this paper. Research done by Filipe Valadares et al.[2] on various rubber replacement ratio and size shows significant benefit in enhancing the abrasion resistance. Thus, an experimental study was conducted to see the behavior of crumb rubber with silica fume on abrasion wear resistance under different water to cement ratio. This testing was carried out to explore the possibilities of CR (without any surface treatment) to resists load from abrasion. The objective of the test was to evaluate the resistance of abrasion due to crumb rubber, different water-to-cement ratio and addition of silica fume as binder.

\section{Mix Design and Specimen Preparation}

In this concrete mix design, CR replacement was $10 \%, 15 \%$ and $20 \%$ of sand by volume. Silica fume, SF with $2200 \mathrm{~kg} / \mathrm{m}^{3}$ density was added at $10 \%$ weight of Ordinary Portland Cement, OPC (density $\left.3160 \mathrm{~kg} / \mathrm{m}^{3}\right)$. The mix design was divided into three main group of water to cement ratio, w/c as shown in Table 1. As for workability, ether-based polycarboxylate superplasticizer was added at $0.5 \%-0.7 \%$ of $5 \%$ maximum allowable dosage. Air content was controlled by using air-entrained

\footnotetext{
a Corresponding author : nurazuwa@uthm.edu.my
} 
agent (to increase air content) for mixing without SF and air-modifying agent (to reduce air content) for mixing with SF. In this study, air content for all mixes was set from $4 \%$ to $5 \%$. Sea sand passing $5 \mathrm{~mm}$ sieve with density of $2580 \mathrm{~kg} / \mathrm{m}^{3}$ and water absorption of $1.72 \%$ which was less than $3.5 \%$ as stated in JIS Standard was used as fine aggregate. Combination of $10 \mathrm{~mm}$ and $20 \mathrm{~mm}$ crushed stone was used as coarse aggregate with density of $2910 \mathrm{~kg} / \mathrm{m}^{3}$. All aggregates were prepared under surface saturated dry condition. Meanwhile, for concrete specimen, diameter, D was $100 \mathrm{~mm}$ and height, $\mathrm{H}$ between $45 \mathrm{~mm}$ to $55 \mathrm{~mm}$. As for example, three small specimens was cut from the origin concrete cylinder $(\varnothing 100 \times 200 \mathrm{~mm})$ as illustrated in Figure1. Surface for each small specimen should be flat and $90^{\circ}$ to ensure uniform surface contact with rotating disc.

Table 1. Mix proportion of rubberized concrete.

\begin{tabular}{|c|c|c|c|c|c|c|c|c|c|c|c|c|c|}
\hline \multirow{3}{*}{ Group } & \multirow[b]{2}{*}{$\mathrm{CR} /(\mathrm{S}+\mathrm{CR})$} & \multirow[b]{2}{*}{$\mathrm{SF} / \mathrm{C}$} & \multirow{3}{*}{$\mathrm{w} / \mathrm{c}$} & \multirow{2}{*}{$\begin{array}{c}\text { Water } \\
\text { W }\end{array}$} & \multirow{2}{*}{$\begin{array}{c}\text { Cement } \\
\text { C }\end{array}$} & \multirow{2}{*}{$\begin{array}{l}\text { Silica } \\
\text { Fume } \\
\text { SF }\end{array}$} & \multirow{2}{*}{$\begin{array}{c}\text { Sand } \\
\text { S }\end{array}$} & \multirow{2}{*}{$\begin{array}{c}\text { Crumb } \\
\text { Rubber } \\
\text { CR }\end{array}$} & \multicolumn{2}{|c|}{$\begin{array}{c}\text { Coarse } \\
\text { Aggregates }\end{array}$} & \multicolumn{3}{|c|}{ Chemical Admixture } \\
\hline & & & & & & & & & G1 & G2 & $\begin{array}{c}\text { Ether-based } \\
\text { polycarboxylate } \\
\text { superplasticizers }\end{array}$ & $\begin{array}{c}\text { Air- } \\
\text { entrained } \\
\text { agent }\end{array}$ & $\begin{array}{c}\begin{array}{c}\text { Air- } \\
\text { modifying } \\
\text { agent }\end{array} \\
\end{array}$ \\
\hline & (Vol \%) & $(\%)$ & & & & & $\mathrm{kg} / \mathrm{m}^{3}$ & & & & $\%$ & $\%$ & $\%$ \\
\hline Control & 0 & 0 & 0.50 & 165 & 330 & 0 & 790 & 0 & 636 & 329 & 0.5 & 0.8 & \\
\hline 10CR-0SF & 10 & & & & & & 711 & 35 & & & 0.5 & 0.8 & \\
\hline 15CR-0SF & 15 & & & & & & 671 & 53 & & & 0.5 & 0.8 & \\
\hline Control & 0 & 0 & 0.35 & 160 & 457 & 0 & 741 & 0 & 608 & 405 & 0.5 & 0.8 & \\
\hline 10CR-0SF & 10 & & & & & & 667 & 34 & & & 0.5 & 0.8 & \\
\hline 15CR-0SF & 15 & & & & & & 629 & 50 & & & 0.7 & 0.8 & \\
\hline 20CR-0SF & 20 & & & & & & 594 & 67 & & & 0.7 & 0.7 & \\
\hline 10CR-10SF & 10 & 10 & 0.35 & 160 & 457 & 46 & 613 & 34 & 608 & 405 & 0.7 & & 1.5 \\
\hline 15CR-10SF & 15 & & & & & & 575 & 50 & & & 0.7 & & 2.2 \\
\hline 20CR-10SF & 20 & & & & & & 540 & 67 & & & 0.7 & & 2.8 \\
\hline
\end{tabular}
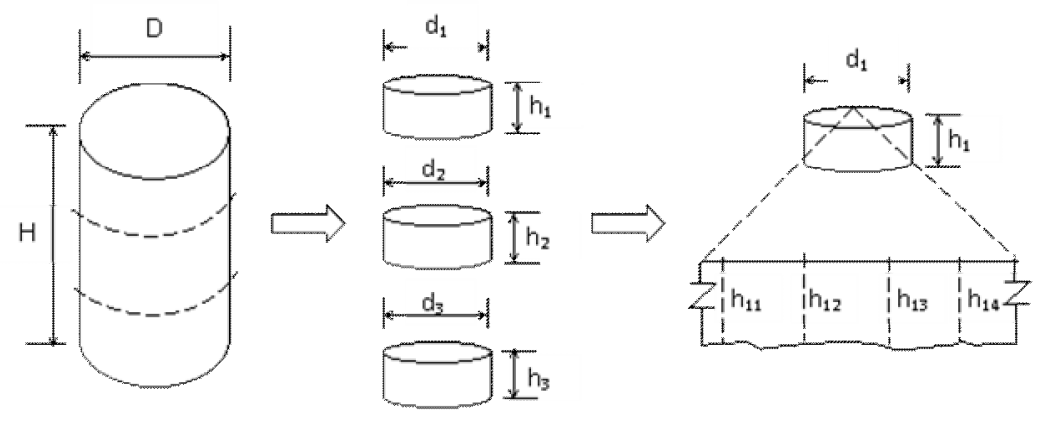

Figure 1. Specimen preparation.

\section{Abrasion Test}

Abrasion wear resistance of rubberized concrete was performed using Dorry abrasion testing machine as shown in Figure 2. It consists of a disc rotating shaft that connected to a motor to facilitate the removal of abrasive material which flow from above reservoir. Specimen was placed in the grip according to the size and then was tightened to ensure firm condition. Grip was then resting on disc rotating surface. Abrasive material used in this research was silica sand as shown in Figure 3. Silica sand was placed in the reservoir and flow down towards the rotating disc to provide friction on specimen surface. Initial data was recorded before each test and then disc was rotated and stop at each 
500 rotation interval. At each interval, the change of weight and depth was recorded; where depth changes were calculated at the average of four points.



(b) Reading rotation

(c) $05 \mathrm{~cm}$ upecimen grip

(d) $010 \mathrm{~cm}$ upecimen grip

Figure 2. Specimen preparation.

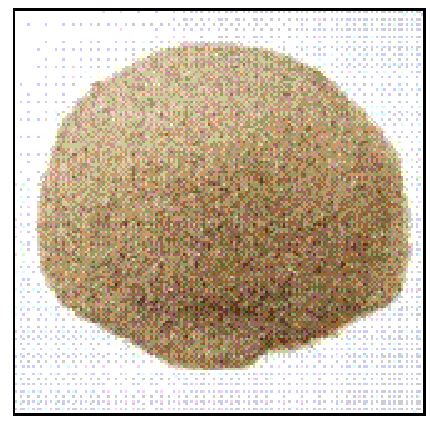

Figure 3. Silica sand.

\section{Results and Discussion}

Figure 4 shows results of surface abrasion wear resistance with the presence of $\mathrm{CR}$ at $10 \%, 15 \%$ and $20 \%$. A larger difference was observed between control mix (0CR-0SF) and mix with CR. At 4000 disc rotation the depth loss was $0.85 \mathrm{~mm}$ compared to mixture with $10 \% \mathrm{CR}$ addition which was $0.62 \mathrm{~mm}$; with $30 \%$ reduction difference. Resistance against surface abrasion wear was continuously improving with $15 \%$ and $20 \%$ CR replacement with depth loss of 0.58 and 0.52 respectively at 4000 disc rotation. Effect of CR added with SF on abrasion resistance is shown in Figure 5. At 4000 disc rotation, the depth loss of rubberized concrete with SF was reducing from $0.85 \mathrm{~mm}$ for control mix to $0.67 \mathrm{~mm}, 0.61 \mathrm{~mm}$ and $0.51 \mathrm{~mm}$ at every $10 \%, 15 \%$ and $20 \% \mathrm{CR}$ addition as sand replacement. 


\section{MATEC Web of Conferences}

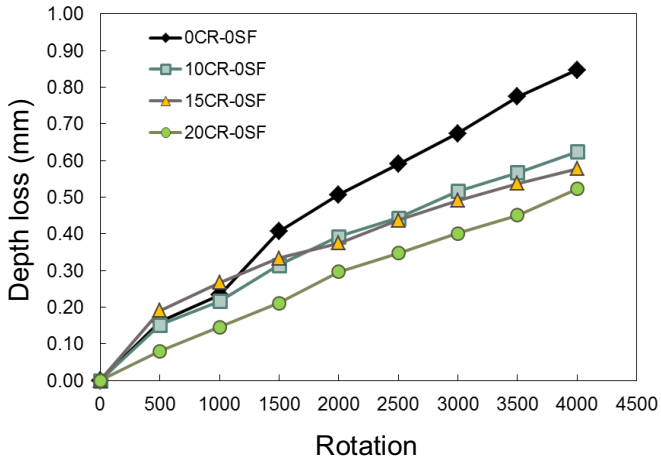

Figure 4. Depth loss of rubberized concrete without silica fume due to abrasion test $(\mathrm{w} / \mathrm{c}=0.35)$.

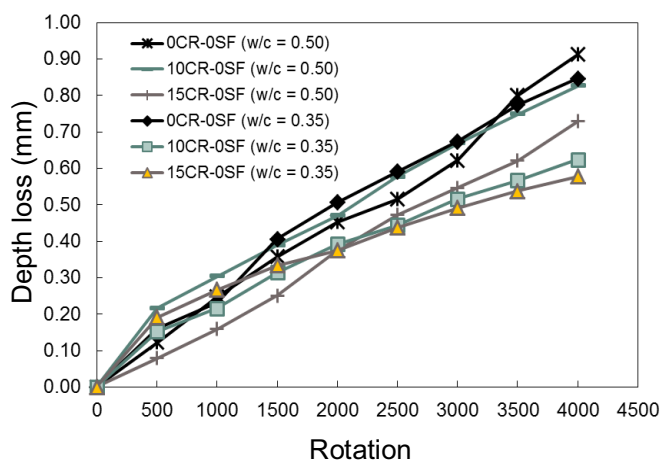

Figure 6. Depth loss of rubberized concrete without silica fume due to abrasion test $(\mathrm{w} / \mathrm{c}=0.50$ and 0.35$)$.

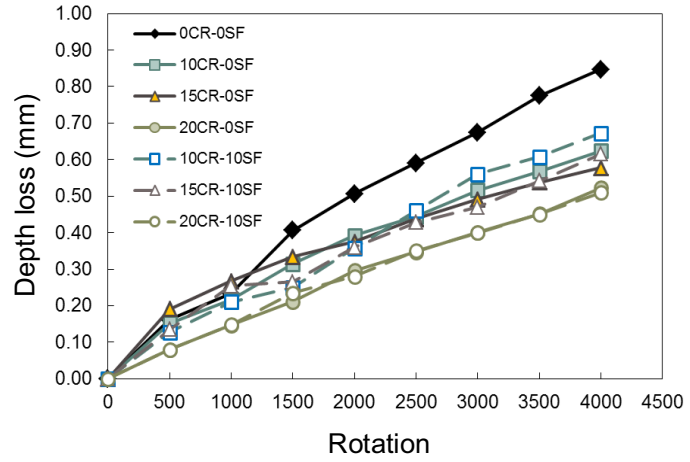

Figure 5. Depth loss of rubberized concrete with silica fume due to abrasion test $(\mathrm{w} / \mathrm{c}=0.35)$.

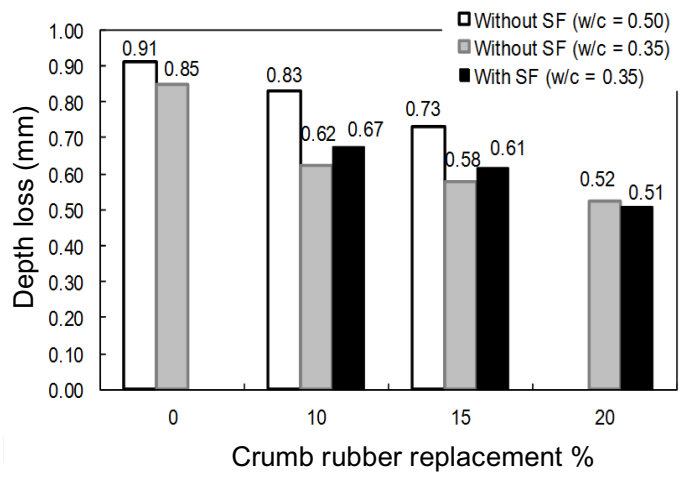

Figure 7. Depth loss of concrete surface at 4000 rotations.

Table 2. Data of abrasion wear resistance at 4000 disc rotations for all mixture.

\begin{tabular}{|c|c|c|c|}
\hline \multicolumn{4}{|c|}{ Abrasion wear resistance at 400 rotation } \\
\hline \multicolumn{2}{|c|}{ Mix } & \multirow{2}{*}{$\begin{array}{c}\begin{array}{c}\text { Compressive } \\
\text { strength, } \\
\text { N/mm2 }\end{array} \\
68.8\end{array}$} & \multirow{2}{*}{$\begin{array}{l}\begin{array}{c}\text { Depth loss, } \\
\text { mm }\end{array} \\
0.85\end{array}$} \\
\hline \multirow{4}{*}{$\begin{array}{l}\text { Without SF }(\mathrm{w} / \mathrm{c} \\
=0.35)\end{array}$} & 0CR-0SF & & \\
\hline & 10CR-0SF & 56.52 & 0.62 \\
\hline & 15CR-0SF & 50.46 & 0.58 \\
\hline & 20CR-OSF & 43.81 & 0.52 \\
\hline \multirow{3}{*}{$\begin{array}{l}\text { With } \\
(w / c=0.35)\end{array}$} & 10CR-10SF & 63.43 & 0.67 \\
\hline & 15CR-10SF & 58.31 & 0.61 \\
\hline & 20CR-10SF & 51.38 & 0.51 \\
\hline \multirow{3}{*}{$\begin{array}{l}\text { Without SF }(\mathrm{w} / \mathrm{c} \\
=0.50)\end{array}$} & 0CR-0SF & 46.18 & 0.91 \\
\hline & 10CR-OSF & 33.72 & 0.93 \\
\hline & 15CR-0SF & 31.89 & 0.73 \\
\hline
\end{tabular}


However, this reduction was slightly larger than mixture without silica fume at $10 \%$ and $15 \% \mathrm{CR}$ replacement and no difference can be concluded for $20 \% \mathrm{CR}$ replacement. Effect of water-to-cement ratio of 0.35 and 0.50 on the depth loss was presented in Figure 6 . As for mixture with $w / c=0.50$ the same reduction pattern with $\mathrm{w} / \mathrm{c}=0.35$ mixture was observed. The depth loss was $0.91 \mathrm{~mm}$ for conventional concrete and $0.83 \mathrm{~mm}$ and $0.73 \mathrm{~mm}$, respectively, for each $10 \%$ and $15 \% \mathrm{CR}$ replacement. Due to the high w/c, the abrasion resistance was smaller compared to $\mathrm{w} / \mathrm{c}=0.35$.

It was clearly seen that $10 \%$ crumb rubber addition as sand replacement provide good resistance than that control mix in all mixes According to Blessen Skariah Thomas et al., this improvement may due to the restriction of the surface grinding due to the CR position which was beyond the smooth surface and acted like a brush [4]. CR with $20 \%$ replacement gave much higher resistance against abrasion with $50 \%$ depth loss difference for both rubberized concrete with and without SF.

Looking back to the effect of SF, it was found that the inverse behavior was seen; where the abrasion resistance of rubberized concrete was much lower than that mixture without silica fume. Generally, it was stated that, higher compressive strength due to $10 \% \mathrm{SF}$ addition gave better abrasion resistance as reported by Ghafoori and Diawara in 1999 [5]. But, when CR was added in mixture with higher compressive strength, the bonding between CR particles and cement matrix started to distress when subjected to friction force and may cause certain CR to jut out from the surface. In this research, this fundamental behavior was observed on specimen with compressive strength higher than 50 $\mathrm{N} / \mathrm{mm}^{2}$ (refer Table 2). This situation indicates that the compressive strength was an important factor affecting concrete abrasion resistance. When dealing with water-to-cement ratio effect, it was noted that higher w/c gave higher loss of surface depth due to small compressive strength value compared to mixture with low w/c. However, as discussed above, there was a limitation of abrasion resistance in relation with strength. This limitation was only applicable for CR without any treatment and this fundamental discovery may be further investigated. Abrasion resistance of high strength mixture could be improved by enhancing the bonding of the matrix by applying certain treatment on the rubber surface.

\section{Conclusion}

Several conclusions can be drawn from this research as follows, (i) The depth loss of concrete surface was decreasing with the increase of crumb rubber volume which indicates that abrasion resistance was improved with the presence of crumb rubber in the mix, (ii) Compressive strength is important factor affecting the abrasion resistance, where abrasion resistance is increase with increasing in compressive strength, and (iii) However in this research, it was found that strength was limited to $50 \mathrm{~N} / \mathrm{mm}^{2}$ due to the lack of crumb rubber elastic modulus to accommodate with high strength of cement paste.

\section{Ackowledgement}

The authors would like to express their gratitude to Hikari World Company Limited for their continuous support in supplying the crumb rubber. Grateful acknowledgement was also dedicated to Malaysian Ministry of Higher Education in providing financial support to the first author.

\section{References}

[1] A. Çavdar and Ş. Yetgin, investigation of abrasion resistance of cement mortar with different pozzolanic compositions and subjected to sulfate medium, Construction and Building Materials, 24, 461-470, (2010).

[2] F. Valadares, M. Bravo and J. de Broti, Concrete with used tire rubber aggregates: mechanical performance, ACI Materials Journal, 109, 283-292, (2012).

[3] G. Sing and R. Siddique, Abrasion resistance and strength properties of concrete containing waste foundry sand (WFS), Construction and Building Materials, 28, 421-426, (2012). 


\section{MATEC Web of Conferences}

[4] B.S. Thomas, R.C. Gupta, P. Kalla and L. Cseteneyi, Strength, abrasion and permeation characteristics of cement concrete containing discarded rubber fine aggregates, Construction and Building Materials, 59, 204-212, (2014).

[5] R. Siddique, Effect of fine aggregate replacement with $\mathrm{f}$ fly ash on the abrasion resistance of concrete, Cement and Concrete Research, 33, 1877-1881, (2003). 